\title{
Large-Scale Influences on Atmospheric River Induced Extreme Precipitation Events Along the Coast of Washington State
}

Allison B. Marquardt Collow ${ }^{1,2}$, Haiden Mersiovsky ${ }^{3}$, and Michael G. Bosilovich ${ }^{2}$

${ }^{1}$ Universities Space Research Association, Columbia, MD

2NASA Global Modeling and Assimilation Office, Greenbelt, MD

${ }^{3}$ Florida State University, Tallahassee, FL

\begin{abstract}
\begin{tabular}{l|ll} 
SUMMARY & Atmospheric Rivers (ARs) are responsible for much of the
\end{tabular} precipitation along the west coast of the United States. In order to accurately predict AR events in numerical weather prediction, subseasonal and seasonal timescales, it is important to understand the large-scale meteorological influence on extreme AR events. Here, characteristics of ARs that result in an extreme precipitation event are compared to typical ARs on the coast of Washington State. In addition to more intense water vapor transport, notable differences in the synoptic forcing are present during extreme precipitation events that are not present during typical AR events. In particular, a negatively tilted low pressure system is positioned to the west in the Gulf of Alaska, alongside an upper level jet streak. Subseasonal and seasonal teleconnection patterns are known to influence the weather in the Pacific Northwest. The Madden Julian Oscillation (MJO) is shown to be particularly important in determining the strength of precipitation associated with in AR on the Washington coast.
\end{abstract}




\section{Background}

ARs, or dynamic, narrow filaments of enhanced integrated water vapor transport (IVT) (Ralph et al., 2018), can account for much of the annual precipitation along the west coast of the United States and are therefore important for the hydrology of the region. Although beneficial at times, ARs can also cause extreme precipitation events that result in flooding and mudslides (Nieman, 2011). An extreme precipitation event is defined as a day in which the area averaged accumulation across the coastal region of Washington State (region outlined in white in Figure 6) exceeds the 95th percentile, or roughly $25 \mathrm{~mm}$. The 95th percentile was computed using all days of the year with at least $1 \mathrm{~mm}$ of precipitation for the climatology period of 1981 through 2010. Extreme events occur most frequently during the cool season, and therefore the months of November, December, and January are focused on here.

\section{Atmospheric Rivers and Water Vapor Transport Associated with Extreme Events}

ARs were detected in MERRA-2 using the TempestExtremes feature tracking algorithm (Ullrich and Zarzycki, 2017) which required a value for IVT that exceeded $250 \mathrm{~kg} \mathrm{~m}^{-1} \mathrm{~s}^{-1}$ in addition to spatial requirements. These criteria used to detect an AR were identical to what was used for the Tier 1 group of experiments for the Atmospheric River Tracking Method Intercomparison Project (ARTMIP; Shields et al., 2018).

An example of an AR associated with a multi-day extreme precipitation event on the Washington coast occurred on 7-9 December 2015. Flooding, mudslides, and power outages were widespread through the area, prompting President Obama to declare it as a natural disaster. The IVT and sea level pressure (SLP) for the days surrounding the event can be seen in the animation at https://gmao.gsfc.nasa.gov/researchbriefs/ NWcoastARprecip influences/IVT-SLP.gif and at the height of the event in the still image in Figure 1. Exceptionally large values for IVT are displayed as red colors, and note the extensive swath of enhanced IVT extending from the central Pacific Ocean to the Pacific Northwest of the United States. A copious amount of water vapor is being funneled between the Aleutian low to the north and the subtropical high to the south. The position and strength of the Aleutian low and subtropical high are extremely important for determining the intensity and location of an AR. This is just one example of an AR associated with an extreme precipitation event in Washington State, however there were 
over 250 of these events during the months of November, December, and January in the MERRA-2 time period of 1980 through 2019.

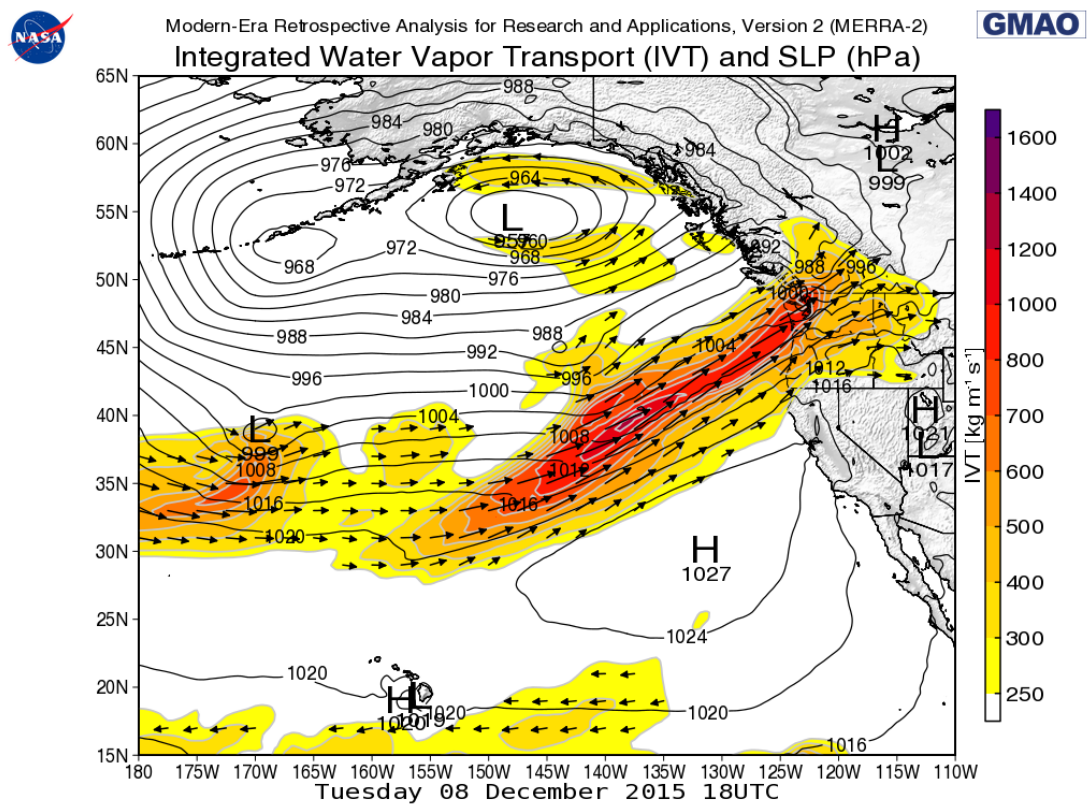

Figure 1: Integrated water vapor transport (IVT, shading) and sea level pressure (SLP, contours) at $18 z$ on 8 December 2015 in MERRA-2.

More can be learned about the properties of ARs associated with extreme precipitation events, and how they differ from a typical AR by compositing atmospheric variables from MERRA-2 across all the detected events. Figure 2 shows the magnitude of the IVT beginning three days prior to an extreme precipitation event induced by an AR, as well as for the days leading to an AR being detected within the region. Given that ARs are dynamical features, this gives an indication of the location and strength of the AR as it progresses in time and space. It is evident that three days prior to an AR on the Washington coast, an AR is present spanning the Pacific Ocean, usually oriented from southwest to northeast (Figure 2a). There is not much difference in the location of the AR between the extreme precipitation and non-extreme AR events, however, as expected, ARs that resulted in an extreme precipitation event had a larger magnitude in IVT in the central west Pacific. There is considerable variability in the IVT this far ahead of an AR landfall and averaging likely smooths out any indication that the location of the AR may differ during an extreme precipitation event. The ARs progress to the north and east, eventually making landfall on the Washington coast, and the difference in intensity of ARs associated with an extreme precipitation event compared to a typical landfalling $A R$ 
continues to become larger in magnitude. The mean magnitude of IVT right along the coast is already above the threshold required for $A R$ the day prior to an $A R$ induced extreme precipitation event. The enhanced IVT associated with extreme precipitation events also suggests that these ARs could have a persisted duration (Payne and Magnusdottir, 2016).

\section{Extreme Events}

(a)

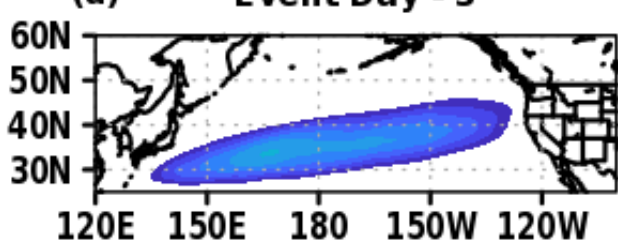

(c) Event Day - 2

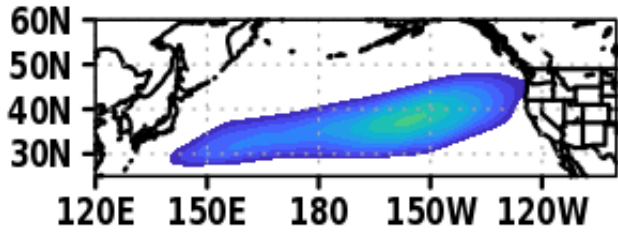

(e) Event Day - 1

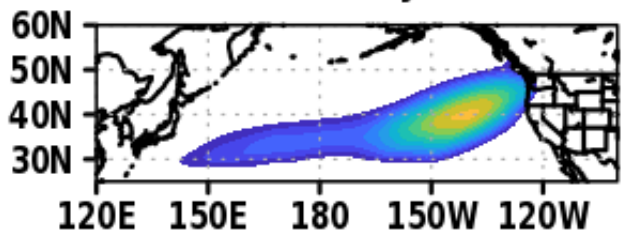

(g)

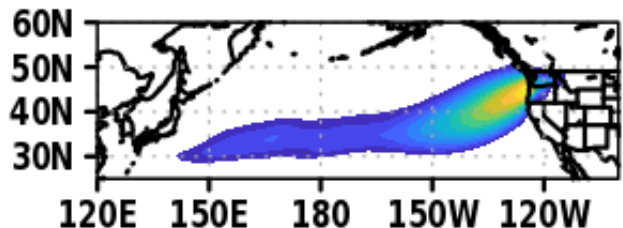

120E 150E 180 150W 120W

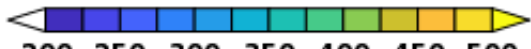

$200 \quad 250300 \quad 350 \quad 400 \quad 450 \quad 500$
Extreme Events - All ARs

(b) Event Day - 3

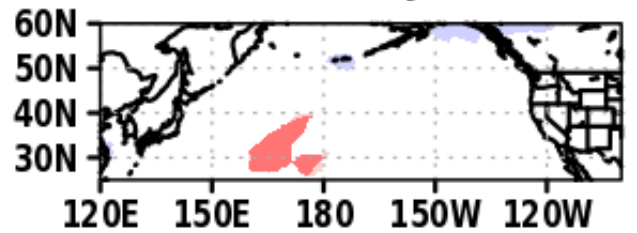

(d)

Event Day - 2

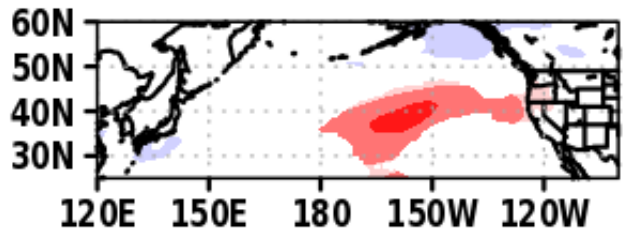

(f)

Event Day - 1

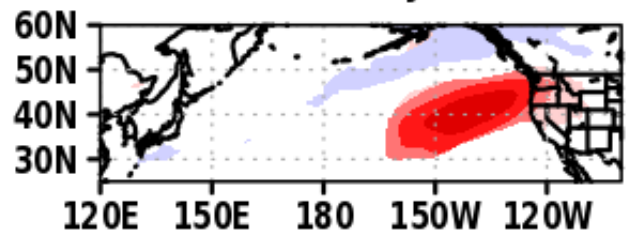

(h)

Event Day

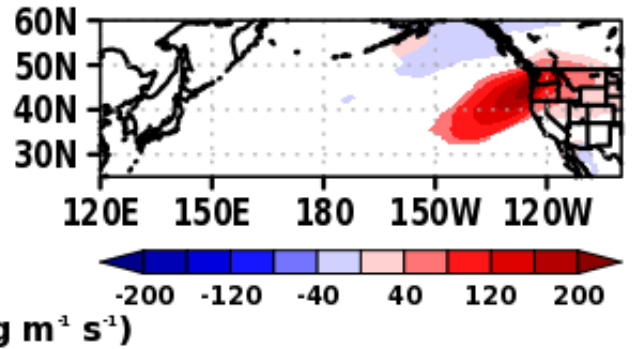

Figure 2: Integrated water vapor transport composited for the three days prior to an AR induced $95^{\text {th }}$ percentile extreme precipitation event (left column) and the difference to days in which an AR (right column) was detected along the coast of Washington State during November, December, and January

1980-2019. Regions in (b, d, f, and h) that are not statistically significant have been masked out. 
Along the coast of Washington and Oregon, the IVT exceeds $500 \mathrm{~kg} \mathrm{~m}^{-1} \mathrm{~s}^{-1}$ on the day of an extreme precipitation event induced by an $A R$, double the minimum threshold to be considered an AR (Figure $2 \mathrm{~g}$ ). On the other hand, the IVT is near the threshold of what would be classified as an AR for all events. There are a lot of weak ARs, as well as ARs in various stages of their lifecycle. The magnitude of the IVT weakens for all ARs on the day of an event from the day prior, mostly because the moisture is rained out without a source for resupply. An additional difference between extreme and non-extreme AR events, not obvious in Figure $2 \mathrm{~h}$, is in the orientation of the AR along the coast. The ARs associated with extreme precipitation events maintain the southwest to northeast orientation after reaching the coast, however, for all ARs, there is a west to east orientation in the immediate area along the Washington coast, as though the subtropical high is shifted to the east during extreme events.

\section{Synoptic Environment During Extreme Events}

Synoptic scale patterns are a key factor for an AR to reach the coast of Washington, particularly through the position and strength of the Aleutian low and North Pacific high, both of which are apparent in the composites of SLP during extreme and all ARs (Figure $3 a$ and $b)$. An eastward position of the Aleutian low in the Gulf of Alaska, climatologically more likely during the early half of the cool season, is more favorable for ARs making landfall on the Washington coast. Regardless of whether an extreme precipitation event occurs, the mean SLP of the Aleutian low is deeper on days with an AR detected and the pressure gradient is more intense on days with an extreme event as evident by the difference in sea level pressure between extreme and all ARs (Figure 3b). Much of this comes from a deeper low, however there is also a stronger high that extends slightly to the northeast. 
(a)

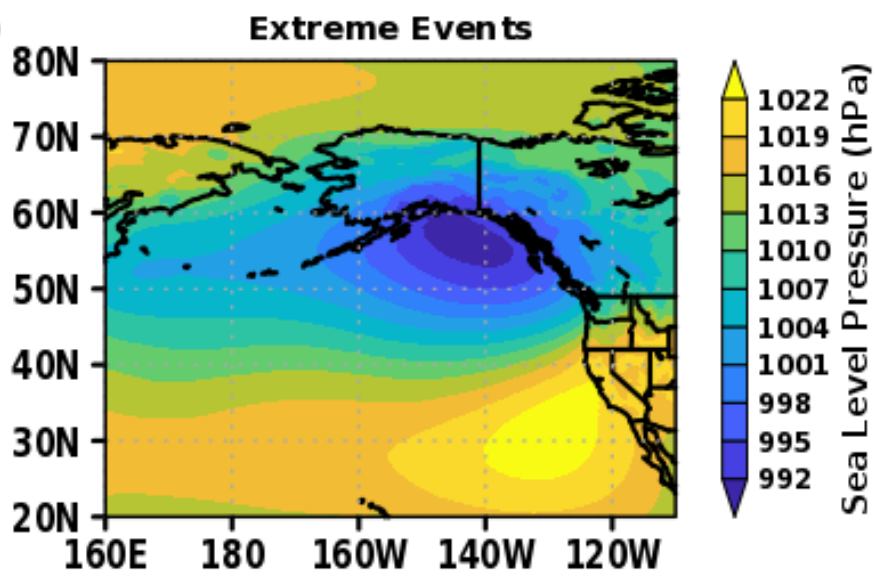

(b)

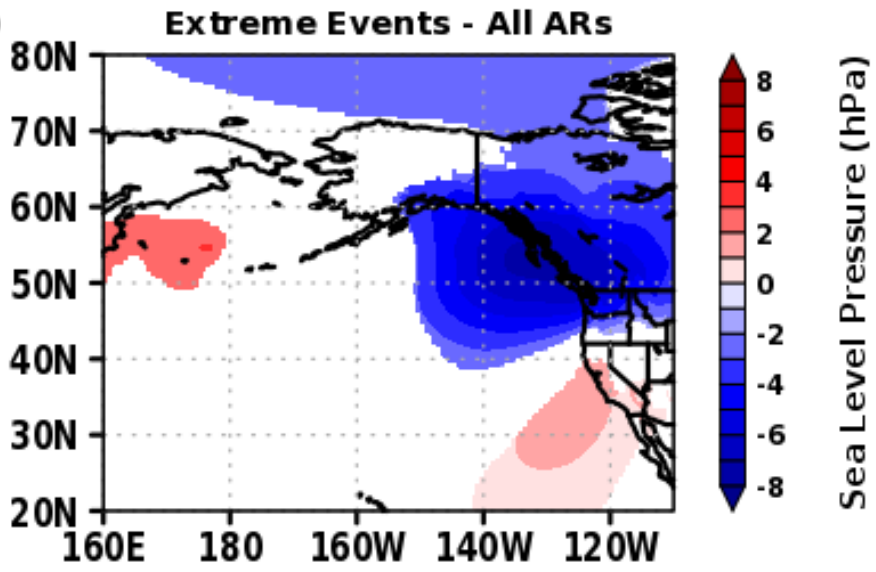

Figure 3: Sea level pressure composited on days with (a) an AR induced 95 th percentile extreme precipitation event and (b) the difference to days with a landfalling AR on the Washington coast during November, December, and January 1980-2019. Regions that are not statistically significant are masked out in (b).

For a different perspective, the anomalies with respect to the zonal mean are shown for $500 \mathrm{hPa}$ heights (Figure 4). There is a clear distinction on days with an extreme precipitation event in the low within the middle troposphere. During extreme precipitation events, a clearly defined low is present in the Gulf of Alaska for a vertically stacked low pressure system (Figure 4a), however this is not the case for all ARs in general (Figure 4b). A deeper low is present for both event types further west, centered at $140^{\circ} \mathrm{E}$. It is generally in the same location regardless of whether there was an extreme precipitation event, although perhaps shifted slightly north for all ARs. A region of high heights is present over the western United States, though stronger and located south and 
west on days with an extreme precipitation event. Overall, zonal anomalies at $500 \mathrm{hPa}$ agree with the sea level pressure in the sense that the gradient between the high and low is tighter for extreme precipitation events. Aside from this, the longwave pattern at $500 \mathrm{hPa}$ is quite similar across the rest of the Northern Hemisphere (not shown).

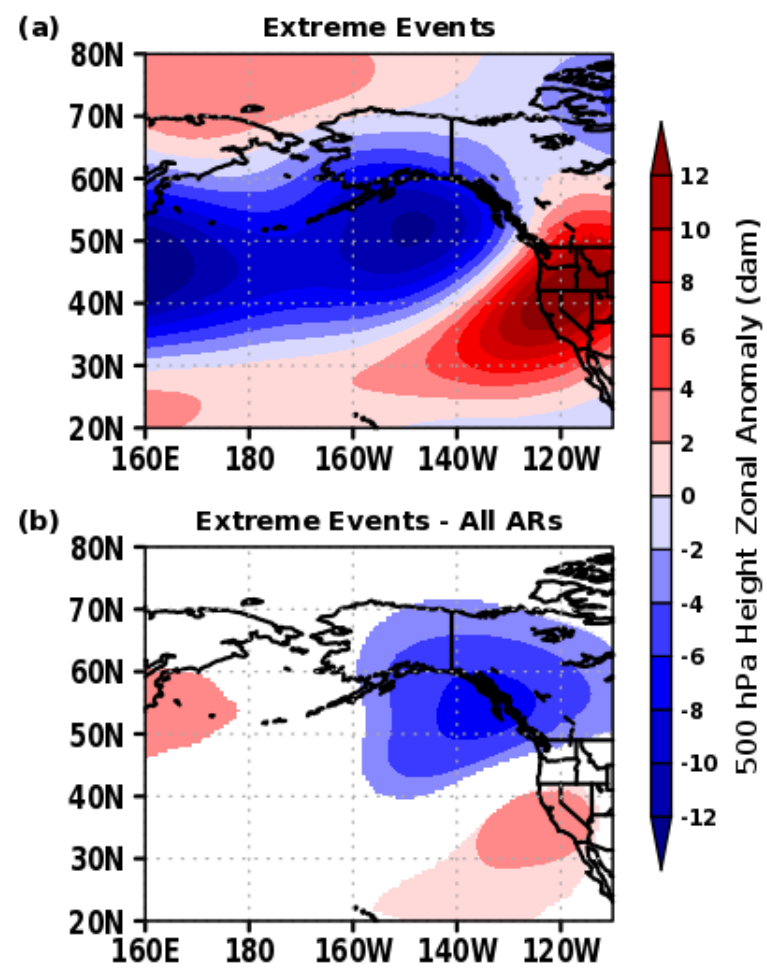

Figure 4: $500 \mathrm{hPa}$ height anomaly with respect to the zonal mean composited on days with (a) an AR induced $95^{\text {th }}$ percentile extreme precipitation event and (b) the difference between an extreme event and days with a landfalling AR on the Washington coast during November, December, and January 1980-2019. Regions that are not statistically significant are masked out in (b).

A $250 \mathrm{hPa}$ jet streak, or region of enhanced wind speed within the jet stream, is present over the region during extreme precipitation events, with mean speeds nearing $50 \mathrm{~m} \mathrm{~s}^{-1}$ (Figure 5a). The direction of the flow is indicative of an upper-level ridge peaking just east of the region. While this ridge is somewhat present for all ARs, the flow is a bit more zonal within the jet stream (Figure 5b). Additionally, the maximum wind speeds are located well to the southwest. Winds are generally weaker for all ARs, consistent with the reduced pressure gradient, though some of this could be related to the larger sample size. Nevertheless, the jet stream still passes over Washington State when an AR is present. 
Payne and Magnusdottir (2014) noted that more extreme ARs are associated with anticyclonic Rossby wave breaking (RWB) in the eastern Pacific that is less extensive for weaker ARs, while Payne and Magnusdottir (2016) noted an inland shift in the location of RWB for persistent ARs.
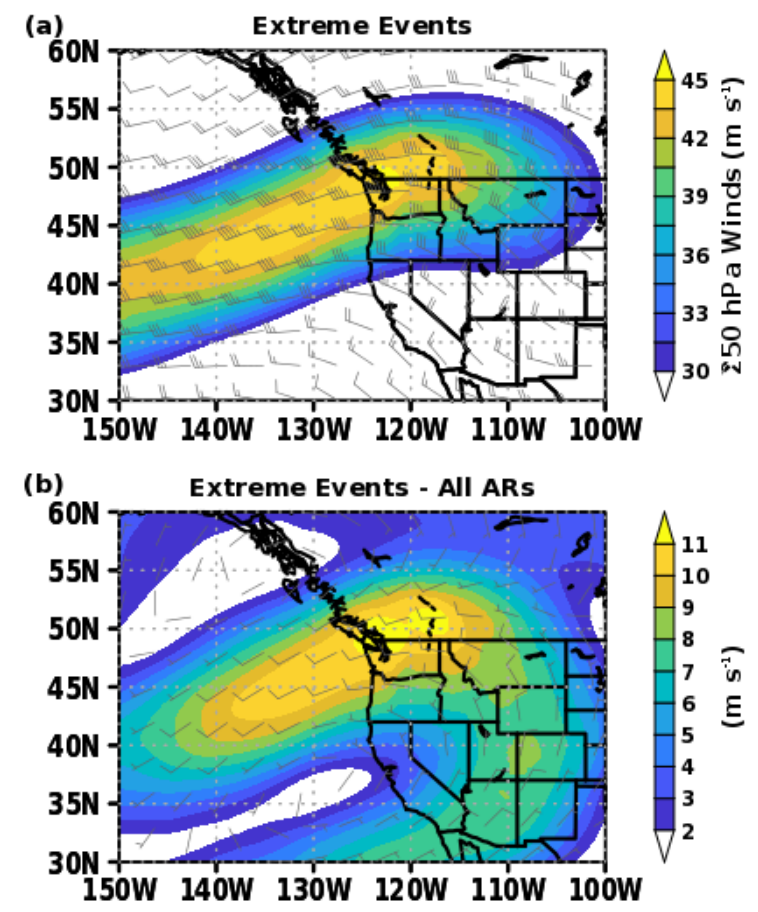

Figure 5: $250 \mathrm{hPa}$ wind composited on days with (a) an AR induced 95th percentile extreme precipitation event and (b) the difference to days with a landfalling $A R$ on the Washington coast during November, December, and January 1980-2019.

\section{Precipitation Associated with Extreme Events}

Spatial maps showing precipitation composited during observed extreme precipitation events from the observations, as well as the MERRA-2 model analyzed and observation corrected precipitation, are displayed in Figure 6. Precipitation in Washington State is greatly influenced by the topography of the Olympic and Cascade Mountains, with larger accumulations falling over higher terrain. The spatial distribution of precipitation is not dependent on whether the event is considered extreme, however, depending on the location, the magnitude is roughly double during an extreme precipitation event. Observations indicate that on days with an extreme precipitation event, on average, 
accumulations can exceed $60 \mathrm{~mm}$ over the Olympic Mountains, with less precipitation elsewhere within the region. As moisture laden air reaches a mountain or sloped terrain, it is forced upward, allowing for condensation and precipitation to occur. This depletes the moisture within the atmosphere and results in less precipitation over the Cascade Mountains.

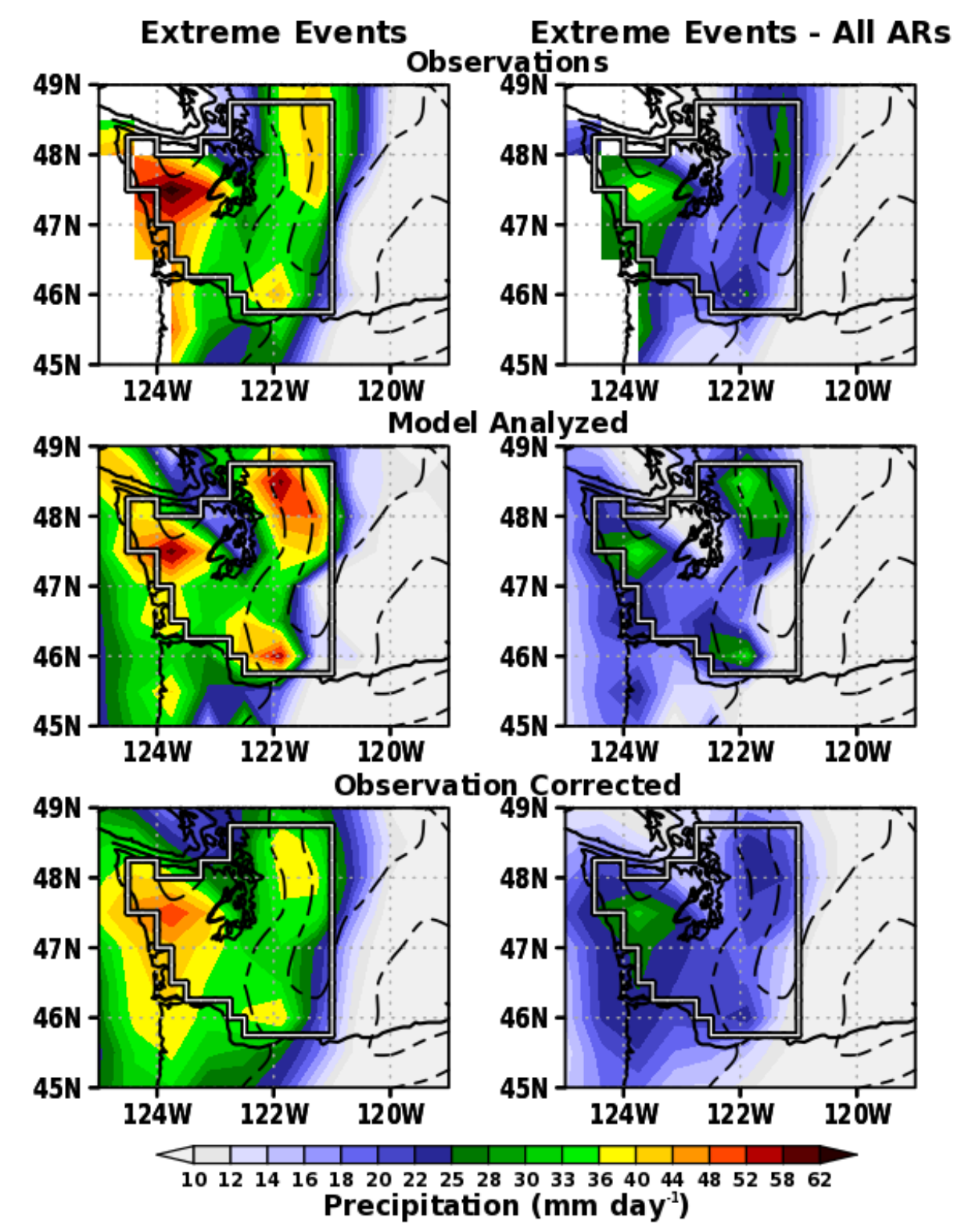

Figure 6: Observed (top row), MERRA-2 modeled (middle row), and MERRA-2 observation corrected precipitation (bottom row) composited on days that an AR induced $95^{\text {th }}$ percentile extreme precipitation event (left column) was observed and the difference to days in which an AR (right column) was detected along the coast of Washington State during November, December, and January 1980-2019. 
Contrary to the observations, MERRA-2 spreads the precipitation out among the Olympic and Cascade Mountains and the model generated precipitation also shifts the northern half of the strip along the Cascade Mountains slightly to the west compared to the observations. This shift is no longer present in the observation corrected precipitation, however somewhat counterintuitively, the magnitude of the precipitation is lower than both the observations and model generated precipitation. As part of the process to determine the correction factor for the observation corrected precipitation, the model background precipitation is aggregated such that the temporal and spatial resolutions of the model and observations match (Reichle et al., 2017). As a result, the observation corrected precipitation is smoothed over the region and the maxima are not as large.

\section{Sub-seasonal and Seasonal Influences}

The influence of teleconnection patterns on landfalling ARs has garnered attention recently in order to make predictions on sub-seasonal and seasonal time scales. ARs were analyzed for teleconnection patterns that have been shown to influence the weather in the Pacific Northwest: on a seasonal timescale, ENSO and the Pacific Decadal Oscillation (PDO), and on a sub-seasonal timescale, the Pacific-North American (PNA) and MJO. Monthly values of the Nino3.4 Index (Rayner et al., 2003) and for the PDO (Mantua et al., 1997) were downloaded from NOAA ESRL's Physical Sciences Division. Daily values of the PNA index were downloaded from NOAA's Climate Prediction Center (Barnston and Livezey, 1987), while daily phase data for the Madden Julian Oscillation (MJO) were downloaded from the Australian Bureau of Meteorology (Wheeler and Hendon, 2004). Table 1 shows the number of events and the normalized phase frequency for these four teleconnection patterns for all ARs and extreme precipitation events such that the value given represents the percentage of days with a given teleconnection pattern that an $A R$ made landfall in Washington. This methodology removes the impact of a given phase of a teleconnection generally being present more frequently than other phases. 

Induced Extreme Precipitation Events Along the Coast of Washington State

Table 1: The number of days with a given phase of a teleconnection pattern as well as the number of days with the teleconnection pattern that had a landfalling AR and extreme precipitation event on the coast of Washington State. Values in parentheses represent the normalized frequency, while the values in the heading represent the total number of days, ARs, and extreme events in November, December, and January 1980 through 2019.

\begin{tabular}{|l|c|c|c|}
\hline \multicolumn{2}{|c}{ Total Days - 3619 } & ARs - 1716 & Extreme Events - 266 \\
\hline EI Nino & 1258 & $621(49.4 \%)$ & $103(8.2 \%)$ \\
\hline La Nina & 1228 & $599(48.8 \%)$ & $85(6.9 \%)$ \\
\hline Neutral ENSO & 1133 & $496(43.8 \%)$ & $78(6.9 \%)$ \\
\hline PDO + & 2060 & $959(46.5 \%)$ & $143(6.9 \%)$ \\
\hline PDO - & 1559 & $757(48.6 \%)$ & $123(7.9 \%)$ \\
\hline PNA + & 2182 & $1123(51.4 \%)$ & $167(7.7 \%)$ \\
\hline PNA - & 1437 & $593(41.3 \%)$ & $99(6.9 \%)$ \\
\hline MJO Phase 1 & 330 & $145(43.9 \%)$ & $28(8.5 \%)$ \\
\hline MJO Phase 2 & 439 & $196(44.7 \%)$ & $24(5.5 \%)$ \\
\hline MJO Phase 3 & 530 & $250(47.2 \%)$ & $37(7.0 \%)$ \\
\hline MJO Phase 4 & 482 & $248(51.5 \%)$ & $37(7.7 \%)$ \\
\hline MJO Phase 5 & 486 & $239(49.2 \%)$ & $42(8.6 \%)$ \\
\hline MJO Phase 6 & 488 & $228(46.7 \%)$ & $36(7.4 \%)$ \\
\hline MJO Phase 7 & 485 & $223(46.0 \%)$ & $31(6.4 \%)$ \\
\hline MJO Phase 8 & 379 & $187(49.3 \%)$ & $31(8.2 \%)$ \\
\hline
\end{tabular}

Payne and Magnusdottir (2014) showed that landfalling ARs along the U.S. west coast occur most frequently during El Niño, but the average landfall latitude during La Niña tended to be along the Washington coast. In a broad sense, our results are in agreement. For AR events impacting coastal Washington, El Niño and La Niña were found to be the most common phases of ENSO 3.4, regardless of whether the AR resulted in an extreme precipitation event. ARs occur less frequently when ENSO 3.4 is neutral. El Niño is slightly more preferential than La Niña for ARs that result in extreme precipitation events. The PDO has been shown to influence water vapor transport through an equatorward shift of the North Pacific AR belt when in the positive phase (Liu et al., 2016) as well as the Aleutian low (Newman et al., 2016), and therefore has the potential to also influence AR 
induced extreme precipitation events on the Washington coast. More ARs were detected along the Washington coast during the positive phase of the PDO, however, when the frequency of occurrence is taken into account, ARs are more probable during the negative phase of the PDO. Like with ENSO, there is little distinction in the phase of the PDO for all ARs compared to those that result in an extreme precipitation event. On a subseasonal scale, the PNA is correlated to temperature and precipitation in the Pacific Northwest (Leathers et al., 1991) as the positive phase for PNA shows a breakdown of the normally prevalent midlevel anticyclone of the Pacific Northwest. The positive phase is more common, but this does not outweigh the fact that $A R s$ and $A R$ induced extreme precipitation events more frequently occur when the PNA is in the positive phase.

Results for the MJO are more interesting as there is a distinction between all ARs and those that resulted in an extreme precipitation event. Extreme event days were more common during the middle and outside phases of the MJO, whereas little distinction can be seen among the MJO phases for all ARs. Phase 8 of the MJO is marked by a prominent trough over the North Pacific and southwesterly winds over the region, making the large-scale circulation ideal for heavy precipitation over the Washington region (Bond and Vecci, 2003). On the contrary, a ridge is present over the Pacific Northwest during phase 2 of the MJO (Bond and Vecci, 2003), explaining why that phase sees the lowest normalized frequency for extreme precipitation events. Phases 1, 5, and 8 are the most preferred for extreme events, which agrees with Payne and Magnusdottir (2014) from the perspective that they saw increased AR activity during phase 8 and a more poleward mean landfalling latitude during phase 5 . This however contradicts their finding that increased AR activity also occurs during phases 6 and 7, and that phase 7 has the largest anomaly in the moisture flux. 

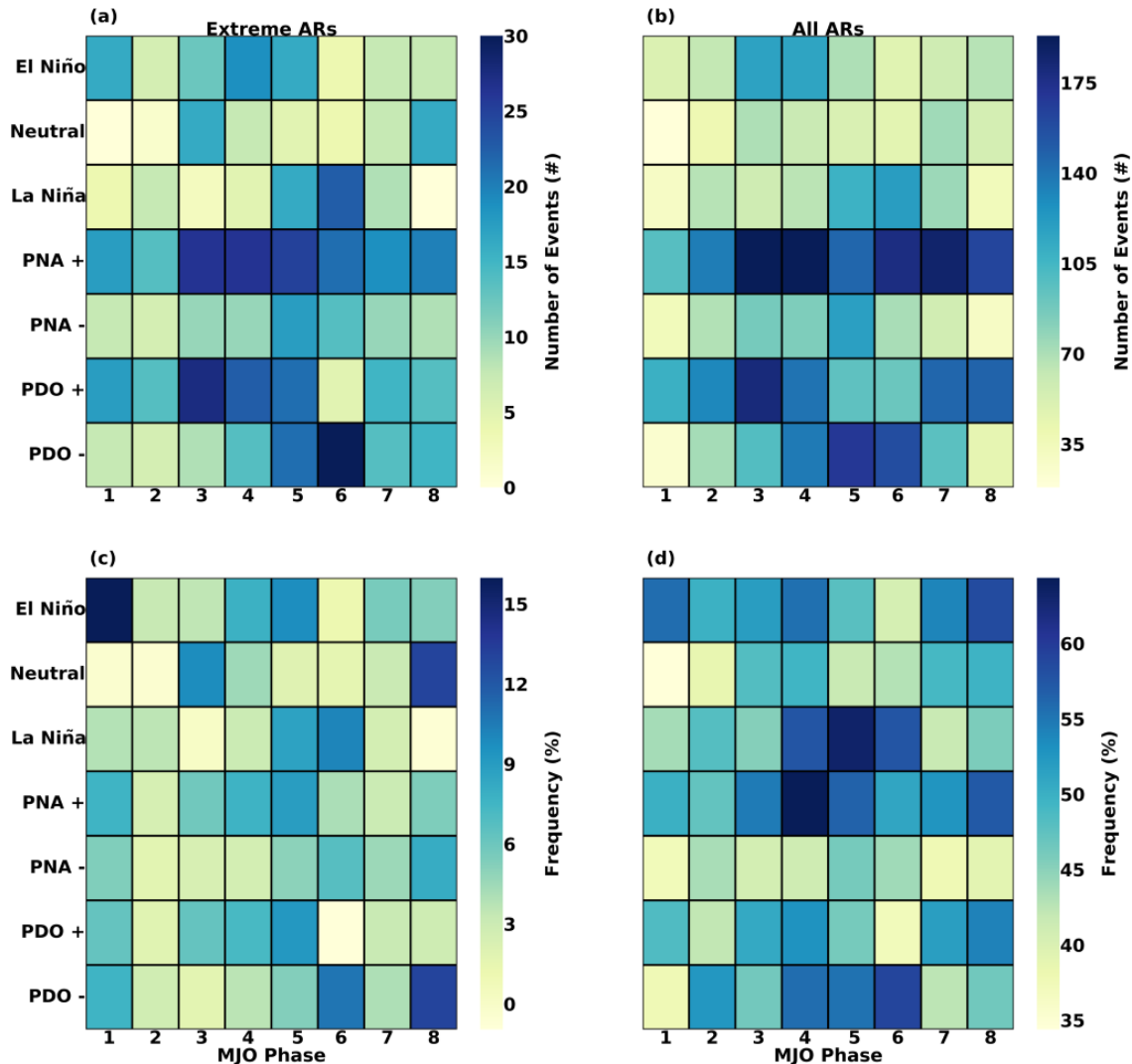

Figure 7: Histogram of the $(a, b)$ count and $(c, d)$ frequency of $(a, c) A R$ induced $95^{\text {th }}$ percentile extreme precipitation events and $(b, d)$ all ARs on the Washington coast for teleconnection patterns during each phase of the MJO during November, December and January.

Teleconnection patterns can interact with one another and given the distinction between all ARs and those that result in an extreme precipitation event associated with the MJO, the MJO is further analyzed with respect to ENSO, PDO, and PNA (Figure 7). While much of what can be seen in Figure 7 duplicates the results already discussed, particularly for the PNA, there are a few additional things that can be learned when considering teleconnections alongside individual MJO phases. Numerous studies have shown that the MJO behaves differently depending on the phase of ENSO, with the MJO propagating faster during El Niño (e.g., Moon et al., 2011). ARs resulting in extreme precipitation events occur most frequently during El Niño conditions when the MJO is in phase 1. During phase 3 of the MJO and La Niña conditions, an anticyclonic anomaly is present over the North Pacific Ocean, thus encouraging dry conditions along the west coast of the United States (Moon et al., 2011). The occurrence of extreme precipitation events is therefore suppressed, with larger counts of events occurring during positive or neutral 
ENSO conditions under phase 3 of the MJO. The synoptic set up during phase 8 of the MJO likely reduces the unfavorable conditions present during neutral ENSO conditions and the weakening of the Aleutian low during the negative phase of the PDO (Mantua and Hare, 2002).

\section{Future Work}

One downfall of studying the statistics of extreme precipitation events associated with ARs is that by definition, they are rare. While the relationship to the MJO documented by data from MERRA2 could be present in nature, there is also the possibility that random chance plays a role when a limited sample size is considered, and this should be considered a precursory evaluation. The opportunity exists to not only confirm the influence of the MJO on AR induced extreme precipitation events in the Pacific Northwest of the United States, but also to evaluate the predictability of such events using the upcoming version of the GMAO's subseasonal to seasonal forecast system, S2S_3.

Portions have been submitted for publication in the Journal of Hydrometeorology.

\section{References}

Bond, N. A., and G. A. Vecchi, 2003: The influence of the Madden-Julian Oscillation on precipitation in Oregon and Washington. Wea. Forecasting, 18, 600-613 doi: 10.1175/1520-0434(2003)018<0600:TIOTMO>2.0.CO;2.

Leathers, D.J., B. Yarnal, and M.A. Palecki, 1991: The Pacific/North American Teleconnection Pattern and United States Climate. Part I: Regional Temperature and Precipitation Associations. J. Climate, 4, 517-528, doi: 10.1175/15200442(1991)004<0517:TPATPA>2.0.CO;2.

Liu, X., X. Ren, and X. Yang, 2016: Decadal Changes in Multiscale Water Vapor Transport and Atmospheric River Associated with the Pacific Decadal Oscillation and the North Pacific Gyre Oscillation. J. Hydrometeor., 17, 273-285, doi: 10.1175/JHM-D-14-0195.1.

Mantua, N. J. and S. R. Hare, 2002: The Pacific Decadal Oscillation. Journal of Oceanography, 58, 35-44, doi: 10.1023/A:1015820616384. 
Moon, J.-Y., B. Wang, and K.-J. Ha, 2011: ENSO regulation of MJO teleconnection. Climate Dynamics, 37, 1133-1149, doi: 10.1007/s00382-010-0902-3.

Newman, M., M.A. Alexander, T.R. Ault, K.M. Cobb, C. Deser, E. Di Lorenzo, N.J. Mantua, A.J. Miller, S. Minobe, H. Nakamura, N. Schneider, D.J. Vimont, A.S. Phillips, J.D. Scott, and C.A. Smith, 2016: The Pacific Decadal Oscillation, Revisited. J. Climate, 29, 4399-4427, doi: 10.1175/JCLI-D-15-0508.1.

Nieman, P. J., 2011: Flooding in Western Washington: The Connection to Atmospheric Rivers. J. Hydrometeor., 12, 1337-1358, doi: 10.1175/2011JHM1358.1.

Payne, A.E. and G. Magnusdottir, 2014: Dynamics of Landfalling Atmospheric Rivers over the North Pacific in 30 years of MERRA Reanalysis. J. Climate., 27, 7133-7150, doi: 10.1175/JCLI-D-14-00034.1.

Payne, A. E., and G. Magnusdottir, 2016: Persistent landfalling atmospheric rivers over the west coast of North America. J. Geophys. Res. Atmos., 121, 13,287-13,300, doi:10.1002/2016JD025549.

Ralph, F.M., M.D. Dettinger, M.M. Cairns, T.J. Galarneau, and J. Eylander, 2018: Defining "Atmospheric River": How the Glossary of Meteorology Helped Resolve a Debate. Bull. Amer. Meteor. Soc., 99, 837-839, https://doi.org/10.1175/BAMS-D-17-0157.1.

Reichle, R.H., Q. Liu, R.D. Koster, C.S. Draper, S.P. Mahanama, and G.S. Partyka, 2017: Land Surface Precipitation in MERRA-2. J. Climate, 30, 1643-1664, doi: 10.1175/JCLI-D-160570.1.

Shields, C.A. et al., 2018: Atmospheric River Tracking Method Intercomparison Project (ARTMIP): project goals and experimental design. Geosci. Model Dev., 11, 2455-2474, doi: 10.5194/gmd-11-2455-2018.

Ullrich, P. and C. Zarzycki, 2017: TempestExtremes: a framework for scale-insensitive pointwise feature tracking on unstructured grids. Geosci. Model Dev., 10, 1069-1090, doi: 10.5194/gmd-10-1069-2017.

Wheeler, M.C. and H.H. Hendon, 2004: An All-Season Real-Time Multivariate MJO Index: Development of an Index for Monitoring and Prediction. Mon. Wea. Rev., 132, 19171932, doi: 10.1175/1520-0493(2004)132<1917:AARMMI>2.0.CO;2. 